\title{
Trans i queerdebatt - Revolutionen som uteblev?
}

Af Jan Wickman

Transpersoner och-praktiker bar utgjort ett ideologiskt slagfält inom delar av köns- och queerforskningen. Artikeln spairar tre skeden $i$ den internationella debatten: paitaglig entusiasm $i$ växelverkan mellan queer-och transtänkare på 1990talet, tilltagande ömsesidig kritik och misstro vid millenieskiftet och slutligen försök att överbrygga de klyftor som bade uppstått. Till slut diskuteras nutida tecken på dessa politiska debatters effekter $i$ sambället.

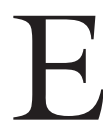

nligt en ofta

upprepad (genesis) uppstod queerperspektivet vid skiftet av 1980- och 1990-talen ur AIDS-aktivismen som en radikaliserande reaktion på hårdnande attityder i samhället gentemot homosexualitet och förödande vanskötsel av AIDS-krisen (se Berg \& Wickman 2010: 15-19). I den östeuropeiska revolutionens efterdyningar präglades eran dock också av att stor politisk förändring framstod som möjlig. Även det queerteoretiska tänkandet, som på 1990-talet fick ett betydande genombrott i akademin, kom snart att medföra en hel del tro på framsteg. ${ }^{1}$ Denna framtidstro kom på ett väsentligt sätt att symboliseras av transgestalter av olika slag. Det fanns två orsaker till detta. För det första, medan queeraktivismen till en början i huvudsak handlade om sexualpolitik fanns queerteorins bas $\mathrm{i}$ poststrukturalistiskt feministiskt tänkande. Kön var en central kategori och transpersoner som på olika sätt kan betraktas överskrida könsgränsen, uppfattades ofta förkropps- 
liga queerteorins centrala teser om både performativitet och dekonstruktion av binärt kön (t.ex. Huuska 1998).

För det andra rapporterades det att en radikalisering även kunde skönjas inom transpolitiken (Bolin 1994; Califia 1997; Garber 1993). Inom den engelskspråkiga världen väckte särskilt det ökande bruket av begreppet 'transgender' intresse och entusiasm. Detta begrepp innebar att det tidigare kategoriska särskiljandet mellan transsexualitet och transvestism avvecklades vilket även kunde tolkas som ett ifrågasättande av man-kvinna-tudelningen. På det sättet kom transpraktiker att betraktas som en konkretisering av den ändringspotential som antyddes i queerteorin. Till exempel Anne Bolin uttryckte entusiastiskt transgenderismens möjligheter på följande sätt: “The transgenderist harbors great potential to deactivate gender or to create in the future the possibility of 'supernumerary' genders as social categories no longer based on biology" (Bolin 1994: 485). Senare har transgender-begreppets utmanande innebörd blivit mindre framstående i och med att det allt oftare började användas även som en synonym för transsexuell (och användningen av blotta prefixet trans har i stället fătt fungera som det samlande uttrycket för hela transfältet), men under första hälften av 1990-talet uttryckte det tydligt nytänkande.

Inspirationen var ömsesidig då queerteorin eggade en del transaktivister. Det queerinfluerade transperspektivet fick i USA några vältaliga språkrör i akademiska debatter. Författare som Sandy Stone, Kate Bornstein, Riki Anne Wilchins och Leslie Feinberg blev kända namn som citerades flitigt. Då de aktivistiska och akademiska debatterna ytterligare sammanföll med en betydande ökning av transpersoners synlighet även i mainstream massmedia och populärkultur, skapades bland många av oss som då följde med dessa debatter ett intryck av att traditionella könsdiskurser väl kunde vara i gungning på bred front, från teorin till den vardagliga praktiken. Inte alla delade dock det entusiastiska omdömet av queer- och transperspektivens förenlighet. Skepticism utrycktes både i transgemenskaperna och inom forskningen. I de följande avsnitten diskuteras de motsättningar som skapade spänningar i debatterna om trans och queer. På vilket sätt kom vissa transoch queerperspektiv att framstå som problematiska för varandra? Hur har man försökt överbrygga klyftorna? Hur ter sig nuläget efter att de mest intensiva debatterna verkar vara över?

\section{TRANS PÅ DET BINÄRA SYSTEMETS VILLKOR?}

Inte alla transpersoner accepterade den tilldelade rollen som avantgarde för en könsrevolution och dekonstruktionen av tvåkönsdiskursen. Framför allt ville många transsexuella leva sitt liv i det kön som de kände som sitt eget och karva sig en plats $i$ det existerande samhället. De upplevde queerdiskursen som främmande och problematisk för sin strävan att få könskorrigeringsprocesserna legitimerade i samhället. Inom några år visade det sig att det skifte mot en betoning av flytande könskategorier som vissa forskare hade applåderat snarare innebar en delning av transpolitiken än en helhetlig transformation av den. Det nya hade uppkommit vid sidan av det gamla snarare än ersatt det (t.ex. Roen 2001; Wickman 2001, 2008).

Det stora teoretiska intresset för trans matchades inte av motsvarande empirisk forskning. Således hördes relativt få transpersoners röster i den akademiska debatt som queertänkandet stödde sig på och det uppstod en misstro mot den (Namaste 1996). Situationen skärptes av en ettrig kritik gentemot transpersoner och -praktiker från ett annat håll på könsforskningens fält. Som en reaktion på den queerinspirerade uppmärksamheten på trans upptogs nämligen nu en radikalfeministisk position som först hade formulerats redan på 1970-talet i 
Janice Raymonds ökända verk The Transsexual Empire (1979/1980) som återutgavs 1993. I detta perspektiv karakteriseras transsexualiteten som antifeministisk, bland annat som en våldsam patriarkalisk intrig för penetrering av autonoma kvinnorum (se t.ex. Jeffreys 1997).

Denna entydiga uteslutning av transsexuella ur kategorin 'kvinna' och från kvinnogemenskaper skiljde den radikalfeministiska positionen distinkt från queerperspektivet. ${ }^{2}$ Den andra anmärkningen mot trans är däremot potentiellt mera förenlig med en queeranalys. Transsexualitet utpekades som ett konservativt medel att normalisera begär att bryta könsnormer (t.ex. Hausman 1995). Medan en sådan kritik rimligtvis kan riktas mot könsstereotypiserande och essentialiserande diagnostik av transsexualitet (se t.ex. Lundgren \& Kroon 1996; Kroon 1997) generaliseras den i radikalfeministisk diskurs ofta oreflekterat till transpraktiker i bredare bemärkelse (Heyes 2003). Trots övergången från kategorin transsexualism till det öppnare begreppet transgender förblev till exempel Raymonds politiska bedömning av trans på 1990-talet negativ.

The ideal of transgender is provocative. On a personal level, it allows for a continuum of gendered expression. On a political level, it never moves off this continuum to an existence in which gender is truly transcended. Its supposedly iconoclastic rebellion against traditional gender confinement is more style than substance. What good is a gender outlaw who is still abiding by the law of gender? (Raymond 1996: 222-223).

I denna stränga kritik av utebliven könsdekonstruktion (som sticker ut av hennes och efterföljarnas i övrigt kraftiga försvar av kategorin 'kvinna' mot transsexuellt intrång) kan Raymond och hennes efterföljare framstå som queerare än queer. Då få framstående queerteoretiker explicit utmanade radikalfeminismens nedvärderande syn på trans, framträdde skillnaden mellan de olika syn- sätten på trans inte med all önskvärd tydlighet för utomstående iakttagare.

Queerforskare som är benägna att undersöka transpraktikernas teoretiska och politiska potential har sällan kommit till lika med kategoriskt avvisande slutsatser som de ovan citerade. Dock har det förekommit, såsom det framgår i de två följande sektionerna, en parallell kritik av transsexuellas växelverkan med medicinsk praxis även i queerdiskurs. En ovanligt skarp formulering av queerteoretiskt motiverad kritik mot könskorrigeringspraxis finns i en studie över Europeiska Människorättsdomstolens avgöranden i fall där transsexualla personer hade överklagat sin hemstats vägran att fastställa deras nya kön som juridiskt giltigt (Sandland 2003). I domstolsbesluten hade en heteronormativt konsekvent presentation av önskat genus utgjort en förutsättning för bestyrkande av den nya könsbestämningen. I slutsatserna ställer forskaren dekonstruktionsprincipen fram om transsexuellas mänskliga rättigheter.

These cases voice the heterosexual desire of law for singularity, the singular truth, the obfuscation of any discontinuity between gender identity and sexuality, for the repositioned certainty that is prepared to stand for some crossing, but no undermining. If this is the price of human rights for transsexuals, then it is not clear that it is a price worth paying (Sandland 2003: 205).

Då en del av dessa rättsavgöranden bekräftar den transsexuella kärandepartens yrkande, vilket dessutom har betraktats som juridiska framsteg av transidentifierade forskare (t.ex. Whittle 2002), är uttalandet problematiskt. Det kan dock ses mot bakgrunden av queerteorins fokus på diskursivt konstruerade subjektspositioner snarare än individer. Begrepp som mänskliga rättigheter hör inte till queerteorins analytiska apparat utan kunde snarare förekomma som föremål för en diskursanalys.

Vanligtvis har queerperspektivet på trans 
dock varit mera nyanserat. Från och med slutet av 1990-talet har queerforskare med emfas betonat att relationen mellan trans och könssystemet inte kan ses som enkelt eller entydigt. Bland annat Butler (1998) konstaterade att olika transpraktiker kan både utmana binärt kön och bidra till att upprätthålla det. Empiriska studier på olika håll i världen pekade på att intresset att utmana eller att anpassa sig till tvåkönssystemet varierade mycket bland transpersonerna själva (Roen 2001; Wickman 2001, 2008).

Att utomstående forskare beaktar transpraktikernas mångfald är viktigt men diskussionens premisser är överhuvudtaget problematiska om den utgår från ett politisk-teoretiskt intresse som har en svag eller snäv koppling till transpersoners egna perspektiv och intressen. Därför var det viktigt att det spektrum av perspektiv som i akademiska debatter representerades av transidentifierade forskare breddades betydligt från och med slutet av 1990-talet. Vid sidan av queerinfluerad radikalism hördes i kultur- och samhällsvetenskaplig debatt nu även röster som kritiskt undersökte den queerteoretiska synen på framför allt transsexuella. Bland de främsta företrädarna av denna diskurs finnes Henry S. Rubin, Jay Prosser och Viviane Namaste. I de två följande avsnitten diskuteras huvudpoängerna i deras kritik: för det första ett försummande i queerforskningen av transsexuella personers erfarenheter, aktörskap och subjektiva upplevelser av identitet samt, för det andra, ett hierarkiskt tänkande som till den grad föredrar transgenderisters synligt och medvetet provocerande könsöverskridande framför transsexuellas mera diskreta könskorrigeringsprojekt, att det leder till ett underkännande av transsexuella livsarrangemang och politik.

\section{DEN BORTGLÖMDA TRANSUBJEKTIVITETEN}

Flera forskare som identifierar sig som transsexuella menar att denna grupps sub- jektivitet, erfarenheter och aktörskap inte känns eller respekteras i queer-teoretisk forskning och diskussion. Viviane Namaste beklagar dessutom att dominansen av den (queer)teoretiska fokuseringen på (konstruktionen av) transidentiteter har överskuggat analysen av de sociala villkor under vilka transsexuella lever och den diskriminering som de möter som transpersoner (Namaste 1996, 2005).

Även om den här kritiken har hörsammats av många forskare är den fortfarande aktuell och tendensen finns kvar i betydande delar av queerforskningen. För att ta ett nordiskt exempel framgår problematiken förmodligen oavsiktligt - bland annat i kapitlet Trans i boken Vad är queer? i vilket Fanny Ambjörnsson presenterar transtemats betydelse för queerforskningen (Ambjörnsson 2006: 135-170). Hon konstaterar inledningsvis att queerbegreppet ofta associeras till ' 'transsexualism', 'transgender', flytande identiteter och obestämbarhet". Hon fortsätter: "Detta är inte en slump. Queerteorin grundas till stor del på just enskilda människors erfarenheter av att falla utanför förväntade genus- och sexualitetskategorier. Queerforskningen handlar därför ofta om till exempel transpersoner (människor som överskrider genusgränserna), butchar, transsexuella eller drag kings" (Ambjörnsson 2006: 135). I behandlingen av de konkreta exempel som tas upp mera detaljerat i slutet av kapitlet blir dock betoningen anmärkningsvärt annorlunda. I motsats till de nämnda erfarenheterna bland transpersoner presenteras först en rätt distanserad undersökning om afro-amerikanska drag queens i Texas som imiterar vita välbärgade medelklasskvinnors femininitet. Här diskuteras hur "detta fenomen" kan eller skall tolkas: Är det ett sätt att tillägna sig vithetens privilegium? Förakt gentemot kvinnor? Underklassens parodi på medelklassen? (Ambjörnsson 2006: 149) Aktörernas egen syn på sin verksamhet framkommer inte. Kontrasten är påtaglig när sedan merparten av kapitlet - efter en 
ytterligare diskussion om butch och femme lesbiska - handlar om personer vars "genusöverskridande" främst handlar om brott mot könskonventioner utan att deras könstillhörighet egentligen blir ändrad eller oklar. Vi möter en amerikansk lesbisk forskare med mexikanskt ursprung, bisexuella kvinnor i Hanna Bertilsdotters intervjustudie (2001) och skoltjejer i Ambjörnssons egen undersökning (2004). Olikt dragqueensen diskuteras dessa individers erfarenheter och några kommer även till tals $\mathrm{i}$ citat. Ambjörnssons sätt att bryta gränserna kring kategorin trans är stimulerande och queerteoretiskt träffande (jmfr. Stryker et al. 2008: 11). Dock skulle en kritiker som Namaste, bekymrad över osynliggörandet av transsubjektiviteter i queerteoretisk debatt, ofrånkomligen reagera på vilka personers röster som blir hörda i kapitlet och vilka som betraktas från ett avstånd.

För att råda bot på problemet med bristfällig uppmärksamhet på subjektiva erfarenheter som uppstod då queerteorin länge hade varit den förhärskande referensramen för forskning om transpersoner, rekommenderade och tillämpade några transidentifierade forskare såsom Henry Rubin (1998) och Jay Prosser (1998) fenomenologiska teorier, vilka utgår från individens förnimmelser och upplevelser. Jag vill dock framhäva att forskarens positionering i relation till de transpersoner och grupper som undersöks är i detta avseende mera avgörande än teoretisk referensram. Även forskning med exempelvis just en fenomenologisk referensram kan resultera i ett utnyttjande av transpersoner i teoretiskt syfte utan hänsyn till deras intressen. I en avhandling på några publicerade memoarer av transmänniskor tillämpade en finsk sociolog, Hanna Vilkka, visserligen en fenomenologisk teori men även ett uttalat 'majoritetsperspektiv' (Vilkka 2006). Enligt henne kan 'majoritetskulturen' dra nytta av transpersonernas gränsöverskridande för sin egen förnyelse. Genom att Vilkka i liberalistisk anda betonade transpersoners individu- ella ansvar för sina öden eftersom det finns exempel på dem som trots allt har nått tillfredsställande livsarrangemang, blev betydelsen av förtrycket av transpersoner förringat (se Wickman 2007).

I transforskningen, som handlar om grupper som utsätts för betydande marginalisering, blir alltså etiska frågeställningar aktuella. Eftersom queerforskningen vanligen har handlat om kritik och dekonstruktion av dominerande diskurser och 'talat från underläget', har dess etik inte varit föremål för omfattande diskussion. De etiska spörsmålen har blivit introducerade $\mathrm{i}$ debatten om transforskningen av akademiker inom närliggande feministiska forskningsfält. Som det framgår i följande avsnitt är deras bidrag betydande, särskilt i metaanalysen av polemiken mellan queer- och transforskare om hierarkier av transpraktiker som har uppstått i queerteoretisk diskussion samt i överbryggande av de schismer som uppstått.

\section{EN QUEER TRANSHIERARKI?}

I transgemenskaper i olika länder förekom det åtminstone på 1990-talet en intern statushierarki som har transsexuella, särskilt post-opererade, på toppen eftersom deras könsöverskridande betraktas som den mest seriösa och framskridna (Halberstam 1998: 147, Wickman 2001: 190). Vissa transidentifierade aktivister och forskare har dock kritiserat queer- och könsforskningen för upprättande av en omvänd hierarki vilken nedvärderar de transsexuella som genomför eller strävar efter möjligast fullständig könskorrigering till den önskade kategorin 'man' eller 'kvinna' eftersom de anses agera på det binära könssystemets villkor (Namaste 2005; Prosser 1998). Katrina Roen och Patricia Elliot har diskuterat denna tendens och dess kritik i en analys av centrala texter av queerinfluerade transaktivister och framstående teoretiker (Elliot \& Roen 1998; Elliot 2009).

När de queera transgenderaktivisterna 
har tagit avstånd från de konservativa positioner som de separatistiska radikalfeministerna har tillskrivit dem, har de ibland kommit att klandra transsexuella som fungerar enligt den medicinska modellen. I The Empire Strikes Back: A Posttranssexual Manifesto såg Sandy Stone transsexualitet som en möjlighet att synliggöra felaktigheten i könsdiskurser som binder identitet till anatomi. Stone beklagade visserligen att den möjligheten och viktig kunskap om kön som uppstår genom de transsexuellas erfarenheter i könskorrigeringsprocessen gick förlorad och förblev osynlig i samhället då många transsexuella vill vara obemärkta ("pass") i sitt nya kön (Stone 1991). Elliot och Roen anser att hon dock inte hyllar det mera synliga könsöverskridandet på bekostnad av de transsexuella i och med att hon skiljer på diskursiva möjligheter och subjektiva identiteter (Elliot \& Roen 1998: 237 238). Kate Bornsteins beryktade och inflytelserika Gender Outlaw (1995) däremot gör en mycket entydigare skillnad mellan å ena sidan 'könskonformister' och å andra sidan utmanare av genus ("gender outlaws") vars medvetna och synliga brott mot könsordningen är vad Bornstein efterlyser och uppskattar. I Transgender Warriors (1996) stöder Leslie Feinberg idén att både kön och sexualitet uppstår utav en komplex samverkan av biologiska och kulturella effekter. Utgående från tanken att könen är många diskuterar Feinberg samhällets begränsningar för hur denna könsmångfald făr komma fram och pläderar för varje persons rätt till kontroll över sin kropp och i förlängningen också över ens könsbestämning. Därför blir texten inte särskilt antitrans-sexuell även om Feinberg klart betonar behovet för ett bredare spektrum av möjligheter och alternativ.

Även i den mera teoretiskt färgade diskussionen har positionerna gentemot transsexualitet varit varierande, men de verkar ha utvecklats i en allt mera accepterande riktning. Judith Butlers Gender Trouble (1990), en av queerteorins obestridda ut- gångspunkter, presenterade teorin om könets performativitet som ursprungligen utlöste det enorma teoretiska intresset för trans. Butler diskuterade sällan sina teoretiska förslag med hjälp av konkreta exempel. Ett av dem var en anmärkning om drag, dock utan hänvisning till något egentligt empiriskt arbete. Detta har setts som ett exempel på hur trans används för ett teoretiskt syfte utan hänsyn till transpersoners liv. Butler återkom dock i Undoing Gender 2004 mera detaljerat till de transsexuellas situation och diskussionen om diagnosens reglerande roll i deras självförståelser, livsval och politik. Hon kritiserar diagnosen för konservativa könsdiskurser om oföränderlig könsidentitet. Vidare ser hon den som stämplande och som ett potentiellt redskap för homofobi, men kräver inte dess avskaffning eftersom den ger vissa viktiga valmöjligheter i det existerande samhället. Hon betraktar inte transsexuella som blint anammande den medicinska synen på transsexualitet och kön, men bekymrar sig för ungdomar som drabbas av diagnosen utan möjlighet till en kritisk syn på den. Därför framstår det dock som ett problematiskt val att utnyttja den medicinskt sanktionerade transsexualitetsdiskursen för att nå ens personliga mål.

Such a discourse $[\ldots]$ holds out the promise, if not the blackmail, that you stand a chance of getting your life, the body and the gender that you want, if you agree to falsify yourself, and in so doing support and ratify the power of this diagnosis over many more people in the future (Butler 2004: 91).

Eftersom sådana etiska dilemman synbarligen inte belastar dem som avstår den medicinska modellen är det förklarligt att Butler har kritiserats för valorisering av transgenderister över transsexuella.

J. Halberstams uppmärksammade Female Masculinity från 1998 handlar bland annat om det som Halberstam kallar "gränskrigen” mellan positionerna som butch lesbisk 
och FTM transgender eller transsexuell. I strävan att komplicera uppvärderingen av transsexuella över andra könsvarianta grupper i transgemenskaper utvecklar Halberstam bland annat en kritik av de transsexuellas diskurs om könsmigration till ett tillstånd som känns som 'hem'. Huvudargumentet är att detta 'hem' inte är tillgängligt för alla. Enligt Elliots analys av Halberstams texter från 1990-talet uttrycks denna kritik så kraftfullt att transgenderidentiteter och -politik faktiskt blir ställda över transsexuella identiteter och -politik på ett alienerande sätt, trots det uttalade målet är att bygga broar och allianser (Elliot 2009: 19-24). I In a Queer Time and Place från 2005 har Halberstam dock modifierat sin position och kritiserar motsättningen mellan transsexuell och transgender på ett, enligt Elliot, mera balanserat sätt (Elliot 2009: 24-27).

Sammanfattningsvis kan det konstateras att det finns betydande variation bland de aktivister och akademiker som har utpekats för att ha gett upphov till en transhierarki som nedvärderar de transsexuella. Det har också skett skiftningar i den riktning att schismen kring denna hierarki har avtagit på 2000-talet (Elliot \& Roen 1998, Elliot 2009: 24-27). Dock har motsättningen inte försvunnit, även om den inte längre är lika central på agendan.

\section{REVOLUTIONEN SOM UTEBLEV?}

På 2000-talet har inte bara de motsättningar som har diskuterats ovan dämpats utan den queerteoretiska diskussionen om trans $i$ allmänhet har avtagit. Den intensitet som präglade debatten på 1990-talet och den speciella relationen mellan queer och trans som kunde skönjas verkar inte finnas längre. Både queerteorin och transforskningen har gått vidare.

Queerteorin fungerar inte längre som den främsta referensramen i transforskning. I stället för att dryfta transidentiteternas och -praktikernas relation till könssystemet kartläggs nu allt oftare transpersonernas liv och sociala situationer. Samtidigt handlar den nyare queerforskningen ofta om andra teman än kropp och kön, vilka med lätthet kunde relateras till transfrågor. Snarare engageras forskarna nu av till exempel postkolonialism och kritik av homonormativitet, homonationalism eller futurism (Berg \& Wickman 2010: 63-85). Dessutom verkar intersexualiteten (medfödd anatomisk oklarhet av kön) allt oftare utgöra det empiriska tema genom vilket gränserna och villkoren för den sociokulturella konstruktionen av kön diskuteras.

Varför verkar då queerteorin ha spelat ut sin roll i transforskningen? Har det som kunde sägas om trans med hjälp av queerteorin helt enkelt blivit sagt? Eller pekar förlusten av positionen som ledande referensram i transforskningen på behov att utveckla queerforskningen i nya riktningar? Eftersom queertänkandet är utpräglat politiskt är det inte långsökt att leta efter tillämpningar i det sociala livet. Dock har svårigheten att kombinera queerteori och sociologi varit föremål för en långvarig debatt. Ur ett sociologiskt perspektiv har queerteorin kritiserats framför allt för en överdriven 'textualism', en underutvecklad förståelse för det sociala samt bristande empirisk förankring (Seidman 1996; Plummer 2005; Berg \& Wickman 2010: 48-62). I den nyare debatten om transforskning efterlyses just fokus på levda erfarenheter i en mångfald av vardagskontexter (Hines 2006; Stryker 2006:2).

De gångna årtiondens queerdebatter har dock knappast passerat utan att lämna spår i samhället eller i transpersoners liv. Även om den könsrevolution som verkade möjlig på 1990-talet inte har ägt rum har betydande ändringar skett. Till exempel den medicinska diskursen, inte minst i Norden, fungerar fortfarande ofta så att den reglerar genusöverträdelser (Hellesund \& Folgerø 2009; Raun 2010: 3-4). Dock kan även ny flexibilitet iakttas. I Finland har sedan 2004 en ny diagnostisk kategori, transgender, införts vid sidan av transsexualitet (Suhonen 
2007). I Storbritannien upplyser till och med en terapeut öppet transpersonerna i sin terapigrupp om könsdekonstruktion, inklusive Butler, och betraktar det som en framgång när några av dem överger sin rigida syn på kön och avstår från den genitalkirurgi som de hade planerat (Hakeem 2010). Fallet är knappast representativt men utgör ändå en ny öppning som hade varit otänkbar på 1990-talet. Även de nyare könskorrigeringslagstiftningarna och förslag för sådana tenderar att visa mera flexibilitet än förut (Wickman 2006). Det beror på perspektivet om dessa justeringar kan betraktas som små segrar som ändrar positionerna från vilka vidare utveckling kan initieras, eller om de måste betraktas som blott en flyttning av gränserna för det som tolereras utan att gränsdragningen i sig blir ifrågasatt.

\section{NOTER}

1. På 2000-talet har Lee Edelmans (2004) kritik mot det nyare västerländska tänkandets framtidsinriktning som heteronormativ väckt stor uppmärksamhet och intresse inom det queerteoretiska tänkandet.

2. Några kritiker förknippade senare trans explicit med queer och förkastade båda företeelserna som kvinnofientliga (t.ex. Jeffreys 2003, Lundgren 2003, Sweeney 2004).

\section{LITTERATUR}

- Ambjörnsson, Fanny (2004): I en klass för sig: genus, klass och sexualiteter bland gymnasietjejer. Ordfront, Stockholm.

- Ambjörnsson, Fanny (2006): Vad är queer? Natur och Kultur, Stockholm.

· Berg, Martin \& Wickman, Jan (2010): Queer. Liber, Malmö.

- Bertilsdotter, Hanna (2001): Biidentiteter: Presentation av en bistudie, i: Lambda Nordica 2001/1-2.

- Bolin, Anne (1994): Transcending and Transgendering: Male to Female, Dichotomy and Diversity, i: Gilbert H. Herdt (ed.): Third Sex, Third Gender: Beyond Sexual Dimorphism in Culture and History. Zone Books, New York.

- Bornstein, Kate (1995): Gender Outlaw: On Men, Women and the Rest of Us. Routledge, New York.

- Butler, Judith (1990): Gender Trouble: Feminism and the Subversion of Identity. Routledge, London. - Butler, Judith (1998): Afterword, i: Sexualities $1 / 3$.

- Butler, Judith (2004): Undoing Gender. Routledge, New York.

. Edelman, Lee (2004): No Future: Queer Theory and the Death Drive. Duke University Press,

Durham.

- Elliot, Patricia \& Roen, Katrina (1998): Transgenderism and the Question of Embodiment, i: GLQ: A Journal of Lesbian and Gay Studies 1998/2.

- Elliot, Patricia (2009): Engaging Trans Debates on Gender Variance: A Feminist Analysis, i: Sexualities $2009 / 5$.

- Feinberg, Leslie (1996) Transgender Warriors: Making History from Joan of Arc to Dennis Rodman. Beacon Press, Boston.

- Garber, Marjorie (1992): Vested Interests: CrossDressing and Cultural Anxiety. Routledge, New York.

- Hakeem, Az (2010) Deconstructing Gender in Trans-Gender Identities, i: Group Analysis 43/2. - Halberstam, Judith (1998): Female Masculinity. Duke University Press, Durham.

- Halberstam, Judith (2005): In a Queer Time an Place: Transgender Bodies, Subcultural Lives. New York University Press, New York.

- Hausman, Bernice L. (1995): Changing Sex: Transsexualism, Technology and the Idea of Gender. Duke University Press, Durham.

- Hausman, Bernice L. (2001): Recent Transgender Theory, i: Feminist Studies 2001/2.

- Hellesund, Tone \& Folgerø, Tor (2009): Transseksualitet på norsk: Heteronormering av kjønn og hverdagsliv, i: Åse Røthing \& Wencke Mühleisen (red.): Norske seksualiteter. Oslo: Cappelen. - Heyes, Cressida J. (2003): Feminist Solidarity after Queer Theory: The Case of Transgender, i: Signs 2003/4.

. Hines, Sally (2006): What's the Difference? Bringing Particularity to Queer Studies of Transgender, i: Journal of Gender Studies 15/1. - Huuska, Maarit (1998): Transseksuaalisen sukupuoli-identiteetin rakentuminen. Tampereen yliopisto, Sosiologian ja sosiaalipolitiikan laitos. Tutkimuksia A:30. Tampere.

- Jeffreys, Sheila (1997): Transgender Activism: A 
Lesbian Feminist Perspective, i: Journal of Lesbian Studies $1 / 3 / 4$.

- Jeffreys, Sheila (2003): Unpacking Queer Politics: A Lesbian Feminist Perspective. Polity Press, Cambridge.

· Kroon, Ann (1997): Att iscensätta kön: Transsexualitet och könskonstituering i psykiatrisk litteratur, i: Anne-Louise Eriksson (red.):

Könssorter(ing): Forskning om kön och makt. Sociologiska instiutionen, Uppsala universitet, Working Paper Series I.

- Lundgren, Eva (2003): Queering Me Softly: Or Expanding Mascilinity? i: NIKK magasin 2003/3. - Lundgren, Eva \& Ann Kroon (1996): Den öppna kroppen och det låsta könet: Den symboliska och dynamiska kroppen speglad mot psykiatrisk konstruktion av transsexualitet, i: Sociologi $i$ dag 1996/4.

- Namaste, Ki (1996): Tragic Misreadings: Queer Theory's Erasure of Transgender Subjectivity, i: Brett Beemyn \& Mickey Eliason (eds.): Queer Studies: A Lesbian, Gay Bisexual and Transgendered Anthology, New York University Press, New York. - Namaste, Viviane (2005): Sex Change, Social Change: Reflections on Identity, Institutions, and Imperialism. Women's Press, Toronto.

- Plummer, Ken (2005): Critical Humanism and Queer Theory: Living with the Tensions, i: Norman K. Denzin \& Yvonna S. Lincoln (eds.): The Sage Handbook of Qualitative Research. Sage, New York.

- Prosser, Jay (1998): Second Skins: The Body Narratives of Transsexuality. Columbia University Press, New York.

- Raun, Tobias (2010): Denmark - A Transgender Paradise? Narrations and negotiations of trans masculinity in Nobody Passes Perfectly, i: Trikster \#4. Lokaliseret 31/5 2011 på http://trikster.net/4/raun/print.html

- Raymond, Janice. (1980 [1979]): The Transsexual Empire. The Women's Press Ltd, London.

- Raymond, Janice (1996): The Politics of Transgenderism, i: Richard Ekins \& Dave King (eds.): Blending Genders: Social Aspects of Cross-dressing and Sex-changing. Routledge, London.

- Roen, Katrina (2001): "Either/Or" and "Both/ Neither": Discursive Tensions in Transgender Politics, i: Signs 27(2).

- Rubin, Henry S. (1998) Phenomenology as Method in Trans Studies, i: GLQ: A Journal of Lesbian and Gay Studies 1998/4.

- Seidman, Steven (1996): Queer Theory/Sociology. Blackwell, Oxford.

- Stone, Sandy (1991): The Empire Strikes Back: A Posttranssexual Manifesto, i: Julia Epstein, \& Kri- stina Straub (eds.): Body Gards: The Cultural Politics of Gender Ambiguity. Routledge, New York. - Stryker, Susan (2006): (De)subjugated Knowledges: An Introduction to Transgender Studies, i: Susan Stryker \& Stephen Whittle (eds.): The Transgender Studies Reader. Routledge, London. - Stryker, Susan \& Currah, Paisley \& Moore, Lisa J. (2008): Introduction: Trans-, trans or transgender, i: Women's Studies Quarterly 36(3-4).

- Suhonen, Malla (2007): Transsukupuolisuuden näkymätön historia, i: Kati Mustola \& Johanna Pakkanen (red.): Sateenkaari-Suomi: Seksuaali-ja sukupuolivähemmistöjen historiaa.: Like \& Vanda stadsmuseum, Helsingfors.

- Sweeney, Belinda (2004): Trans-ending Women's Rights: The Politics of Trans-inclusion in the Age of Gender, i: Women's International Forum $2004 / 27$.

- Vilkka, Hanna (2006): Keho: Omaa sukupuolta koskeva tiedon ja ymmärryksen muotoutumisen perusta transsukupuolisilla. Helsingfors Universitet/ Helsinki University Printing House, Helsingfors. -Whittle, Stephen (2002): Respect and Equality: Transsexual and Transgender Rights. Cavendish, London.

- Wickman, Jan (2001): Transgender Politics: The Construction and Deconstruction of Binary Gender in the Finnish Transgender Community. Åbo Akademis Förlag, Åbo.

- Wickman, Jan (2006): Lagen, medicinen och definitionen av kön: Byte av juridiskt kön som hälsovårdsåtgärd, i: Sirpa Wrede \& Elina Oinas (red.) Det sunda livets trainga ramar: Essäer om det socialt konstruerade könet. Social och kommunalhögskolan vid HU, Forskningsinstitutet, SSKH Skrifter 22, Helsingfors.

- Wickman, Jan (2007): Vastukset sukupuolisen itsemäärittelyn ja sukupuolijärjestelmän uudistamisen edellytyksinä, i: Sosiologia 2007/4.

- Wickman, Jan (2008): Hur handlingsmiljön formar aktivism: Transgenderdiskurser i Finland och USA på 1990-talet, i: Lise Kanckos \& Ralf Kauranen (red.): Social sambörighet och religion. Festskrift till Susan Sundback. Åbo Akademis förlag, Åbo.

\section{SUMMARY}

Trans in queer debates - the revolution that did not happen?

Trans people have become an ideological battle ground in parts of gender and queer 
studies. The article traces the trans/queer relation in international scholarly debates from an enthusiastic exchange of ideas in the 1990s to increasing mutual criticism and mistrust around the turn of the millennium as queer was seen by some as a problematic approach that easily ends up in erasure of trans people's subjective experiences, and further to attempts to bridge such splits that had emerged. Finally, I discuss how queer perspectives seem to have contributed to increased flexibility in medical and legal approaches even if they are criticised for being illequipped for sociological analyses.

Jan Wickman, Pol.Dr.

NIKK, Nordiska institutet for kunnskap om Kjønn Oslo 